\title{
Study on the Relationship Among Perception of Organizational Change, Job Insecurity and Turnover Intention: from the Perspective of Stress Appraisal and Coping*
}

\author{
Linsheng Xiao \\ Beijing Institute of Technology, Zhuhai \\ Zhuhai, China 519088
}

\begin{abstract}
Based on the stress appraisal and coping model of Lazarus and Folkman, this study, uses a sample of 414 teachers from different colleges and universities of China to probes into the influence of organizational change perception on teachers' turnover intention, and tests the mediating role of job insecurity in the relationship between them. It is found that the perception of change frequency has a positive effect on teachers' job insecurity and turnover intention. The perception of change plan has a negative effect on teachers' job insecurity and turnover intention. Teachers' job insecurity has a positive effect on turnover intention, which plays an intermediary role in the perception of change frequency, perception of change plan and turnover intention. This research has provided the beneficial enlightenment for the university to change management.
\end{abstract}

Keywords-perception of organizational change; job insecurity; turnover intention; the stress appraisal and coping model; college teachers

\section{INTRODUCTION}

Today, with increasingly fierce competition and unpredictable environments, organizations can cope with a wide range of challenges only through change. No matter what form the organizational change takes, it is obvious that effective change in management is essential to the survival and development of the organization in the background of normalization of change today. Lewin (1951), who studied organizational change earlier, argues that change is a cognitive process that is accomplished by acquiring new concepts and information. Amiot and Terry (2006) and Fugate et al. (2008) also found that successful response to change depends on the psychological bias of employees. Lattuch and Young (2011) argue that it is necessary for organizations to understand the change situational factors that influence employees' cognitive appraisal and behavioral trends to better manage change. Rafferty and Griffin (2006)

*This paper is a phased achievement of Guangdong provincial key platform and the major scientific research innovation project (educational research project) (project number: 2016GXJK197) and the research and development fund project of Beijing Institute of Technology, Zhuhai (project number: XK-2015-28). point out that if you don't know which characteristics of the change situation are negative and are associated with poor outcomes, it is difficult to implement successful change.

Previous researchers have found that organizational change can create a sense of job insecurity for employees and lead to employees' turnover intentions. For example, Hui (2000) believes that when organizations change, employees worry that available resources will be reduced, and their own interests will be damaged, etc., which will make members of the organization feel insecure; Ashford et al. (1989) point out that organizational change will lead employees to feel insecure and further generate the idea of turnover. Wang Jieying (2013) finds that job insecurity has a partial mediating effect on perception of organizational change. The common feature of such researches is that they all believe that organizational change has a negative impact on employees, but does not examine the contextual characteristics and impact of organizational change; this also means that the revelation of the intermediary mechanism for job insecurity made by such researches is also thick and inadequate.

The stress assessment and coping theory of Lazarus and Folkman (1984) argues that whether an individual feels pressure on a stress event and what strategy they will implement depend on the individual's cognitive appraisal of stress events. The process of cognitive appraisal can be defined as the process by which an individual categorizes the events encountered. Mishra and Spreitzer (1998) further pointed out that employees will judge the nature of stress events. If they believe that the event is not threatening to them, they will show a tendency to constructive reaction; if they believe that the event is threatening to them, they will show a tendency of destructive reaction. Although organizational change is considered as an important source of stress for employees' work and life (Hellriegel, Slocum, \& Woodman, 2001), organizational change itself is complex, and employees' perceptions and subsequent responses to organizational change contextual characteristics will not be purely positive or negative. Therefore, it is necessary to identify the employee's cognitive appraisal of the contextual 
characteristics of organizational change in order to predict and judge their impact on organizational change. Rafferty and Griffin (2006) believe that the change frequency, the change plan and the impact of change are the three most important contextual characteristics that employees can perceive from organizational change, and they find that the three factors have different impacts on employees' cognitive appraisal and behavioral tendencies. Among them, the frequency of change refers to the frequency of changes that individual perceives in the organization. A planned change is an individual's perception of the organization's consideration and readiness to implement change. The impact of change refers to the degree of change that individuals perceive in the way of working, values, organizational structure, technical means, and strategy in the organization.

In recent years, Chinese universities have undergone continuous changes in personnel distribution systems, logistics socialization, academic systems, and personnel training models. As human beings enter the era of digitalization and intelligence, traditional educational concepts and talent training models will face enormous challenges. In addition, the intensification of competition in enrollment, faculty, scientific research, and personnel training at home and abroad will be an inexhaustible motive force for continuous change in colleges and universities.

Based on the stress appraisal and coping theory of Lazarus and Folkman, this study uses Rafferty and Griffin's three-dimensional model of perception of organizational change to explore the perceptions, attitudes and behavior tendency of college teachers on change by using survey samples from 414 teachers from different universities, hoping to provide enlightenment for organizational change management of universities through this research.

\section{LITERATURE REVIEW AND RESEARCH HYPOTHESIS}

\section{A. Perception of Organizational Change and Job Insecurity}

The emergence of insecurity is an anxiety and negative emotion that occurs when people feels that information cannot be grasped or recognize an objective threat (De Witte, 1999). Greenhalgh and Rosenblatt, early researchers at work insecurity, argue that job insecurity is "incapable of maintaining ongoing work in a threatened work situation." Salter (1998) defines job insecurity as a concern or uncertainty about the sustainability of future work. In short, job insecurity is the individual's negative reaction to changes in work and the threatening perception and emotional experience of losing work.

Lazarus and Folkman (1984) identified the time attributes of some events, including the urgency of the event, the duration and uncertainty of time that would have a negative impact on the individual. Guo Shuang (2007) points out that the intensity of stress is closely related to the frequency of negative life events experienced by individuals. Studies have also shown that when change events are frequent, employees feel that the future is highly unpredictable, leading to an increase in anxiety (Glick et al., 1990). Ashford (1989) points out that the larger the number of organizational changes is, the more serious sense of job anxiety the employees will have.

Lazarus and Folkman (1984) argue that the greater the change in a situation is, the more uncontrollable the outcome will be, and the greater the perceived threat to the individual becomes. Bordia et al. (2004) find that organizational change often leads employees to have the perception of insecurity in the current state of work. This is because organizational change often leads to major changes in the human structure and organizational structure. Employees are forced to face an uncertain future, worrying about the reduction of available resources and the loss of their own interests, which will make the members of the organization full of sense of insecurity.

Lazarus and Folkman (1984) point out that the unpredictability of change leads to a negative perception of change. Therefore, the plan that comes with change is the issue that employees are most concerned about (Korsgaard et al., 2002). Griffin et al. (2004) find that planned and step-bystep changes can increase employee engagement in change actions and promote employee's mental health. In general, planning before the change will make the change predictable, thus reducing the occurrence of sudden and unpredictable events. Based on the above points, the following assumptions are proposed:

H1a: perception of Change frequency has a positive impact on teachers' job insecurity, which means the more frequent the perceived changes are, the stronger the teacher's job insecurity will be;

H1b: perception of Change impact has a positive predictive effect on teachers' job insecurity, which means the greater the perceived change impact is, the stronger the teacher's job insecurity will be;

H1c: perception of Change plan has a negative impact on teachers' job insecurity, which means the more complete the perceived change plans and preparations are, the lower the teacher's job insecurity will be.

\section{B. Perception of Organizational Change and Turnover Intention}

In the field of organizational behavior, turnover intentions are often seen as outcome variables that are influenced by a certain cognition or attitude. Colarelli (1984) points out that turnover intention is the behavior and intention of employees who deliberately want to leave the existing work environment or position, or actively seek other job opportunities after working in the organization for a period of time. Porter et al. (1974) argue that turnover intentions are the next withdrawal behavior after employees experience dissatisfaction. The turnover intention is the best predictor of whether employees' turnover will occur (Mobley, 1978).

Vakola and Nikolaou (2006) find that the uncertainty of organizational change is a source of work stress, which reduces employee organizational commitment and increases employee turnover intentions. In the employee turnover model built by Lee and Mitchell (1994), organizational 
change is seen as an important impact factor affecting employee turnover, which is expected to prompt employees to make well-thought-out decisions about their work, which in turn leads to turnover. Rafferty and Griffin (2006) argue that employee perceptions of the change impact and the change frequency may have a direct impact on individual behavioral performance, including a negative impact on job satisfaction and a positive impact on employee turnover. Accordingly, the following assumptions are proposed:

H2a: perception of Change frequency has a positive impact on teachers' turnover intentions, which means the more frequent the perceived changes are, the higher the teacher's turnover intention will be;

H1b: perception of Change impact has a positive predictive effect on teachers' turnover intention, which means the greater the perceived change impact is, the higher the teacher's turnover intention will be;

In addition, Griffin et al. (2004) find that planned and step-by-step changes can increase employee engagement in change actions and promote employee's mental health. Accordingly, this paper predicts and proposes that:

$\mathrm{H} 2 \mathrm{c}$ : perception of the change plan is negatively related to the teacher's turnover intention, which means the more complete the change plan and preparation that the teacher perceives, the lower the turnover intention will be.

\section{The Mediation Role of Job Insecurity in Perception of Organizational Change and Turnover Intention}

According to the stress appraisal and coping theory (Lazarus \& Folkman, 1984), the individual's coping style to stress is determined by cognitive appraisal. Individuals judge the attributes of stress events, and the outcome of the judgment will determine whether the employee's response is constructive or destructive (Mishra \& Spreitzer, 1998). Amiot and Terry (2006) argue that the characteristics of change indirectly affect employees' coping choices through the intermediary role of individual contextual assessment. They use longitudinal data to study the cognitive appraisal and coping strategies of employees after the company's merger. The results show that employees' participation and information communication in the process of change can promote the formation of positive cognitive appraisal of employees, and positive change perception has a positive impact on job satisfaction and organizational identity. Researches of Rafferty and Griffin (2006) explore the impact of change frequency, change impact and change plan on psychological uncertainty and job satisfaction, and reveal in depth the intermediary mechanism of psychological uncertainty in change perception and employee attitude and behavioral bias. Based on the above viewpoints, this study proposes the following assumptions:

H3a: The sense of job insecurity plays a mediating role between the perception of change frequency and turnover intention;

$\mathrm{H} 3 \mathrm{~b}$ : The sense of job insecurity plays a mediating role between the perception of change impact and turnover intention;
H3c: Work insecurity plays a mediating role between the perception of change plan and turnover intention.

\section{RESEARCH METHODS}

\section{A. Research Object}

560 teachers from dozens of colleges and universities participated in the survey of this project. A total of 360 paper questionnaires and 200 electronic questionnaires were distributed. Among them, the paper questionnaire was distributed in twice, and the electronic questionnaire was distributed once. After finally recovering 468 questionnaires and eliminating the invalid questionnaires, the effective data was 414 , and the effective recovery rate was $88.46 \%$. The basic situation of the sample: (1) gender: 198 male teachers; 216 female teachers. (2) Age: 88 persons aged 30 years old and below; 192 persons aged 31 to 40 years old; 95 persons aged 41 to 50 years old; 39 persons aged 51 years old and above. (3) Job Title: 95 and 186 people have the primary and intermediate titles respectively, accounting for $67.9 \%$ in total 133 have the senior titles (including the vice high), accounting for $32.1 \%$. (4) Education background: Undergraduate and below, masters and doctoral degrees are 86, 222 and 106 respectively. (5) Working years: 90 people with a working period of 2 years or less in the school; 79 people with 3 to 5 years; 107 people with 6 to 10 years; 138 people with working years of 11 years or more.

\section{B. Research Tools}

1) Perception of organizational change: The organizational change perception scale developed by Rafferty and Griffin (2006) is used. The scale consists of three dimensions, namely the change frequency, the change plan and the change impact, for a total of nine items. The scale uses the Likert 5-point scoring method, ranging from "Strongly disagree" to "strongly agree" with 1 to 5 points. In this study, the internal consistency coefficient of the scale is 0.71 , and the internal consistency coefficients of the three dimensions are $0.76,0.79$, and 0.79 , respectively.

2) Job insecurity: The Job insecurity scale developed by Feather and Rauter (2004) is used. The scale consists of 3 items, using the Likert 5-point scoring method, ranging from "strongly disagree" to "strongly agree" with 1 to 5 points. In this study, the internal consistency coefficient of the scale is 0.73 .

3) Turnover intention: The turnover intention scale designed by Fan Jingli (1978) was adopted. The scale contains 4 items. The scale uses the Likert 5-point scoring method, which ranges from "completely inconsistent" to "fully matched" with 1-5 points respectively. In this study, the internal consistency coefficient of the scale is 0.87 .

4) Control variables: This study selected several common demographic variables as control variables, including gender, age, education, professional title, and working years. Previous studies have shown that demographic variables such as gender, age, education, seniority, and rank have a certain degree of correlation with 
organizational behavior and employee psychological response (Wu Zongyou, 2008).

\section{DATA ANALYSIS AND RESUltS}

\section{A. Constructive Discriminant Validity Test}

AMOS21.0 was used to make confirmatory factor analysis for the change frequency, change plan, change impact, job insecurity and turnover intention to test the discriminant validity of the five variables. As shown in "Table I", the five-factor model has the best fit index compared with the single-factor and three-factor models, indicating that the discriminant validity of the five variables involved in this study is good.

TABLE I. CONFIRMATORY FACTOR ANALYSIS RESULTS

\begin{tabular}{clllllll}
\hline model & \multicolumn{1}{c}{$\boldsymbol{\chi 2}$} & \multicolumn{1}{c}{$\mathbf{d f}$} & $\boldsymbol{\chi 2} \mathbf{2} \mathbf{d f}$ & \multicolumn{1}{c}{ GFI } & CFI & TLI & RMSEA \\
\hline Five-Factor Model & 263.12 & 94 & 2.80 & 0.92 & 0.94 & 0.93 & 0.07 \\
Three-Factor Model & 1047.48 & 101 & 10.36 & 0.71 & 0.68 & 0.62 & 0.15 \\
One-Factor Model & 1978.61 & 104 & 19.02 & 0.56 & 0.37 & 0.47 & 0.21 \\
\hline
\end{tabular}

${ }^{\text {a. }}$ Five-factor model: change frequency; change plan;change impact; job insecurity; turnover intention.

b. Three-factor model: change frequency + change plan + change impact; job insecurity; turnover intention.

${ }^{c}$. Single factor model: change frequency + change plan + change impact + job insecurity + turnover intention. work insecurity was significantly positively correlated with the change frequency $(\mathrm{r}=0.14, \mathrm{p}<0.01)$, and was significantly negatively correlated with the change plan $(\mathrm{r}=-0.38, \mathrm{p}<0.01)$, and negatively correlated with the change impact but is not significant. The turnover intention was significantly positively correlated with the change frequency and job insecurity $(\mathrm{r}=0.26, \mathrm{p}<0.01 ; \mathrm{r}=0.27, \mathrm{p}<0.01)$, and was significantly negatively correlated with the change plan ( $r=-$ $0.22, \mathrm{p}<0.01$ ) and positively related to the change impact but is not significant.

\section{Descriptive Statistical Analysis}

The mean, standard deviation and correlation coefficient of each variable are shown in "Table II". The data show that

TABLE II. DESCRIPTIVE STATISTICS FOR EACH VARIABLE

\begin{tabular}{|c|c|c|c|c|c|c|c|c|c|c|c|}
\hline variables & M & SD & 1 & 2 & 3 & 4 & 5 & 6 & 7 & 8 & 9 \\
\hline 1. gender & 0.48 & 0.50 & & & & & & & & & \\
\hline 2. age & 2.21 & 0.88 & $0.16^{* *}$ & & & & & & & & \\
\hline 3. job title & 2.14 & 0.83 & $0.16^{* *}$ & $0.65 * *$ & & & & & & & \\
\hline $\begin{array}{l}\text { 4. education } \\
\text { background }\end{array}$ & 2.05 & 0.68 & 0.10 & $0.14 * *$ & $0.31 * *$ & & & & & & \\
\hline 5. working year & 2.71 & 1.15 & 0.05 & $0.60 * *$ & $0.62 * *$ & 0.08 & & & & & \\
\hline Change frequency & 3.25 & 0.71 & -0.04 & 0.09 & 0.03 & 0.00 & $0.11^{*}$ & & & & \\
\hline change plan & 3.07 & 0.74 & 0.02 & $-0.23 * *$ & $-0.28 * *$ & $-0.22 * *$ & $-0.17 * *$ & $-0.12 *$ & & & \\
\hline 8. Change impact & 3.22 & 0.70 & 0.08 & 0.06 & 0.02 & 0.06 & $0.10^{*}$ & $0.35 * *$ & $0.21 * *$ & & \\
\hline 9. job insecurity & 2.72 & 0.53 & -0.04 & -0.02 & -0.07 & 0.04 & -0.01 & $0.14 * *$ & $-0.38 * *$ & -0.04 & \\
\hline $\begin{array}{l}\text { 10. turnover } \\
\text { intention }\end{array}$ & 2.80 & 0.83 & 0.01 & $-0.10 *$ & -0.07 & 0.08 & $-0.11 *$ & $0.26^{* *}$ & $-0.22 * *$ & 0.08 & $0.27 * *$ \\
\hline
\end{tabular}

Note: $(1) * * p<0.01,{ }^{*} \mathrm{p}<0.05$; (2) Gender: $1=$ male, $0=$ female. Age: $1=30$ years old and below, $2=31$ to 40 years old, $3=41$ to 50 years old, $4=51$ years old and above. Title: $1=$ primary, $2=$ intermediate, $3=$ deputy senior, $4=$ senior Education: $1=$ undergraduate and below, $2=$ master, $3=$ doctor Working age is the number of years of work in the school, including: $1=2$ years and below,

\section{Hypothesis Test}

The mediating effect test method proposed by Baron and Kenny (1986) was used to verify the mediating effect of job insecurity in organizational change and turnover intention through hierarchical regression. Since mediating effect means a causal chain - the mediator variable is caused by the independent variable and affects the change of the dependent variable. As shown in "Table 2", since perception of change impact is not significantly related to job insecurity and turnover intention, in the hypothesis test below, only the relationship between perception of change frequency, perception of change plan, job insecurity, and turnover intention is verified.

According to the data in "Table III", after controlling the demographic variables, the change frequency has a significant positive impact on teachers' job insecurity (M2, $\beta$ $=0.14, \mathrm{p}<0.01)$. The change plan has significant negative influence on job insecurity. (M3, $\beta=-0.43, \mathrm{p}<0.001$ ), and $\mathrm{H} 1 \mathrm{a}, 1 \mathrm{c}$ were verified. The change frequency has a significant positive impact on turnover intention (M5, $\beta=$ $0.28, \mathrm{p}<0.001$ ), and the change plan had a significant negative impact on turnover intention $(\beta=-0.25, \mathrm{p}<0.001)$, so $\mathrm{H} 2 \mathrm{a}, 2 \mathrm{c}$ were validated. In Model 6 (M6), work insecurity has a significant effect on turnover intention $(\beta=0.23, \mathrm{p}<$ 
$0.001)$, and the change frequency on the turnover intention was weakened $(\beta=0.25, p<0.001)$, indicating job insecurity partially mediate the impact of the change frequency on turnover intentions. In Model 8 (M8), work insecurity has a significant effect on turnover intention $(\beta=0.20, p<0.001)$, and the negative effect of the change plan on turnover intention is weakened $(\beta=-0.17, p<0.01)$, which indicates that the sense of job insecurity partially mediates the impact of the change plan on turnover intentions. H3a, $3 \mathrm{c}$ got data support.

TABLE III. TEST ON THE MEDIATION EFFECT OF WORK INSECURITY

\begin{tabular}{|c|c|c|c|c|c|c|c|c|}
\hline & \multicolumn{3}{|c|}{ Job insecurity ( $\beta$ ) } & \multicolumn{5}{|c|}{ Turnover tendency $(\beta)$} \\
\hline & M1 & M2 & M3 & M4 & M5 & M6 & M7 & M8 \\
\hline $\begin{array}{l}\text { Control variables } \\
\text { gender }\end{array}$ & -0.04 & -0.03 & -0.01 & 0.02 & 0.03 & 0.04 & 0.04 & 0.04 \\
\hline age & 0.04 & 0.03 & -0.01 & -0.07 & -0.09 & -0.10 & -0.10 & -0.10 \\
\hline job title & $-0.15^{*}$ & -0.13 & $-0.22 * * *$ & -0.01 & 0.02 & 0.05 & -0.05 & -0.01 \\
\hline education & 0.08 & 0.08 & 0.01 & 0.09 & 0.09 & 0.07 & 0.05 & 0.05 \\
\hline $\begin{array}{l}\text { background } \\
\text { working year } \\
\text { independent } \\
\text { variable }\end{array}$ & 0.05 & 0.03 & 0.06 & -0.07 & -0.11 & -0.12 & -0.07 & -0.08 \\
\hline $\begin{array}{l}\text { change frequency } \\
\text { change plan } \\
\text { mediating variable }\end{array}$ & & $0.14^{* * *}$ & $-0.43 * * *$ & & $0.28^{* * * *}$ & $0.25 * * *$ & $-0.25 * * *$ & $-0.17 * *$ \\
\hline $\begin{array}{l}\text { job insecurity } \\
\mathbb{R}^{2}\end{array}$ & 0.01 & 0.03 & 0.18 & 0.02 & 0.10 & $\begin{array}{l}0.23 * * * \\
0.15\end{array}$ & 0.08 & $\begin{array}{l}0.20 \text { **** } \\
0.11\end{array}$ \\
\hline$\Delta R^{2}$ & & 0.02 & 0.17 & & 0.08 & 0.07 & 0.06 & 0.03 \\
\hline $\mathrm{F}$ & 1.13 & $2.23 *$ & $15.02 * * *$ & 1.86 & $7.38 * * *$ & $10.17 * * *$ & $5.90 * * *$ & $7.29 * * *$ \\
\hline
\end{tabular}

Further, this study uses the non-parametric Bootstrap method popular in recent years to test the mediating effect of job insecurity. According to the test procedure proposed by Preacher and Hayes (2008), the results show that under the 95\% confidence interval, the confidence intervals of the Bootstrap test are $(0.0097,0.0749)$ and $(-0.1479,-0.0435)$ respectively, which do not contain 0 , indicating job insecurity plays a mediating role in the change frequency and turnover intentions, and change plans and turnover intentions. In addition, after controlling the mediation variables, the influence of independent variables (change frequency and change plan) on the dependent variable (turnover intention) is still significant. This indicates that work insecurity plays a partial mediating role. Thus, $\mathrm{H} 3 \mathrm{a}, 3 \mathrm{c}$ are verified.

\section{CONCLUSION}

\section{A. Conclusions}

At present, the literature on the cognitive, attitude and behavioral tendency of college teachers to organizational change from the perspective of organizational behavior is rare. Based on the stress appraisal and coping theory of Lazarus and Folkman (1984), this study uses the threedimensional model of perception of organizational change proposed by Rafferty and Griffin (2006) to explore the influence of college teachers' organizational change perception on turnover intention and the intermediary role of job insecurity. The study puts forward nine hypotheses. After empirical tests, seven hypotheses are proved and two are not.

1) Relationship between organizational change perception and job insecurity: Previous research has often regarded individual perceptions and attitudes as negative factors that hinder the success of change (Van de Ven \& Poole, 2005). In addition, many researchers are concerned with specific changes (such as layoffs, mergers, acquisitions, etc.) and their impact (Cartwright \& Schoenberg, 2006; Fugate, Kinicki, \& Scheck, 2010), but unfortunately they did not identify the nature of the change event that has negative impact on employees. This study takes the three key situational characteristics perceived by employees in the organizational change process as independent variables to explore their differential impact on job insecurity. The study found that the more changes employees perceive, the stronger the work insecurity is, which is consistent with the findings of Ashford et al. (1989). The perception of change plan is negatively related to the teacher's job insecurity, indicating that the more complete the organizational change preparation is and the clearer the plan and goals are, the lower the teacher's job insecurity will be.

2) Relationship between perception of organizational change and turnover intention: The study found that perception of change frequency is positively related to turnover intention, which indicates that the more frequent the organizational change is, the stronger the employee's turnover intention is; the perception of change plan is negatively related to the turnover intention, indicating that the planning of organizational change can reduce the employee's turnover intention. The study also finds that the change impact on job insecurity and turnover intentions is not significant. According to Lewin (1951), organizational change generally goes through the process of "thaw-reformrefreezing". The change impact defined by Rafferty and Griffin (2006) refers to the transformation of the core system of the organization, such as the values, structure, working methods or strategies. This transformation is unlikely to happen overnight. Therefore, the teacher's 
cognitive appraisal of the important results and influence of college change must be manifested in the "change" stage, especially in the "refreezing" stage. In addition, this study used a cross-sectional study that only studied at a single time point and could not obtain information on changes in the ongoing development of organizational change, which may be an important reason why research hypotheses have not been verified.

3) Mediating role of job insecurity: The study also validated the mediating role of job insecurity in the perception of change frequency, the perception of change plan and turnover intention. According to the stress appraisal and coping theory, the individual's evaluation of the interaction process between specific people and situations affects their psychological state, thus affecting the way they choose to cope. Amiot and Terry (2006) also argue that the characteristics of change indirectly affect employees' coping choices through the intermediary role of individual contextual assessment. Therefore, the higher the change frequency perceived by teachers is, the stronger their job insecurity will be, and this will further motivate them to generate the idea of turnover; the more prepared the change plan is perceived by the teacher, the less the job insecurity will be, which will further weaken the employee's turnover intention. The difference of this study from the research of Ashford et al. (1989), Zeng Zhihong (2004), Wang Hao (2013), etc. is that, given the complexity of the change itself and the multidimensionality of employees' perceptions of the changing situational characteristics, this study uses the three-dimensional model of organizational change perception of Rafferty and Griffin (2006) as the basis to reveals more deeply the mediating mechanism of job insecurity in change perception and turnover intention.

\section{B. Practice Enlightenment}

This study provides useful enlightenment for the implementation of effective change management for organizations including universities:

First, a prudent and thoughtful change plan is a prerequisite for a successful change. The primary task of organizational change is to portray the blueprint for change, clarify the goals and direction of change, and form a more complete change plan. The conclusions of this study suggest that a prudent and thoughtful change plan will reduce employees' job insecurity and reduce the likelihood of negative response strategies such as employee avoidance and distancing.

Second, we should promote organizational change steadily. The research results show that the higher the frequency of change is, the higher the employee's job insecurity and the stronger the turnover intention is. Conversely, the less frequently the change occurs, the more likely it is to be considered a discrete event, and the employee will be able to identify a clear starting and ending point (Glick et al., 1990). For organizations, frequent changes increase employees' sense of threat, frustration, and anxiety associated with job insecurity and uncertainty. Therefore, the organization should steadily promote change and strive to avoid the mindset of changing for change or practice of changing the policies frequently.

Third, successful change requires a good job in employees' emotional management. As mentioned earlier, employees' response to change and the perception of change process are key factors for success of change. Therefore, it is very important to understand employees' perceptions of organizational change. The managers of change must understand and grasp the psychological reactions of organizational members in the face of change, and help people to remove negative psychological burdens and enhance positive emotions. Therefore, it is important for the promoters of change to identify, encourage and utilize the positive emotions of employees. Only in this way can we reduce the resistance to change and achieve effective change.

\section{Research Limitations and Future Prospects}

There are still some shortcomings in this study. First, although the anonymity and confidentiality of the questionnaires were emphasized to the participants during the survey, because the study collected data by self-report, there are inevitably psychological implications and social appreciating effects, which will affect the authenticity and reliability of the research conclusions. Second, although the paper questionnaire was distributed twice, the study is still essentially a cross-sectional study. Future research had better collect longitudinal data over a large time span to make the causal relationship between variables be tested more scientifically and rigorously. Third, the variables selected in this study are limited, which focus only on the relationship between organizational change perception, job insecurity and turnover intention. The stress appraisal and coping theory point out that the coping resources owned by individuals will directly affect the individual's cognitive appraisal of situational changes. Therefore, in future research, consideration should be given to including resource responses (such as organizational support) into the research framework to more accurately and comprehensively explore employees' organizational change perception and stress response issues.

\section{REFERENCES}

[1] Fan Jingli. Research on the Turnover Behavior of Female Employees in Textile Mills. National Chengchi University, 1978.

[2] Guo Shuang. Research on the Characteristics and Relationship between College Students' Psychological Stress and Coping Style. Liaoning Normal University, 2007.

[3] Tong Ling. Research on the Impact of Job Insecurity on Turnover Intentions - with Organizational Commitment as an Intermediary. Southwest University, 2014.

[4] Wang Jieying. The Influence of Organizational Political Perception and Organizational Change Perception on the Turnover Tendency- Taking Job Insecurity as a Intermediate Variable. National Sun Yat-Sen University, 2013.

[5] Wu Zongyou. Job Satisfaction and Organizational Commitment of Authoritarian Leaders and Subordinates: The Mediation Process of Trust and the Moderating Effect of Emotional Intelligence. The research of native Chinese Psychology, (30), 3-63, 2008. 
[6] Zhou Hao, Long Lirong. Statistical Test and Control Method for Common Method Deviation. Advances in Psychological Science, 12(6), 942-950, 2004.

[7] Zeng Zhihong. An Empirical Study on the Expected Organizational Change in Job Insecurity and Employee Job Response - Taking Kaohsiung County Regional Hospital as an Example. National Sun Yat-Sen University, 2004.

[8] Amiot, C. E., Terry, D. J., Jimmieson, N. L., \& Callan, V. J. (2006). A longitudinal investigation of coping processes during a merger: implications for Job Satisfaction and Organizational Identification. Journal of Management , 32(4), 552-574.

[9] Ashford, S. J., Lee, C., \& Bobko, P. (1989). Content, Causes, and Consequences of Job Insecurity: a Theory-based Measure and Substantive Test. Academy of Management Journal, 32(4), 803-829.

[10] Baron RM, Kenny DA.(1986).The Moderator-mediator Variable Distinction in Social Psychological Research: Conceptual, Strategic, and Statistical Considerations.Journal of Personality \& Social Psychology , 51 (6) :1173.

[11] Bordia, P., Hobman, E., Jones, E., Gallois, C., \& Callan, V. J. (2004). Uncertainty during Organizational Change: Types, Consequences, and Management Strategies. Journal of Business \& Psychology, 18(4), 507-532.

[12] Cartwright, S., \& Schoenberg, R. (2006). Thirty Years of Mergers and Acquisitions Research: Recent Advances and Future Opportunities. British Journal of Management, 17(S1), S1-S5.

[13] Colarelli, S. M. (1984). Methods of Communication and Mediating Processes in Realistic Job Previews. Journal of Applied Psychology, 69(4), 633-642.

[14] Hans De Witte. (1999). Job Insecurity and Psychological Well-being: Review of the Literature and Exploration of Some Unresolved Issues. European Journal of Work \& Organizational Psychology, 8(2), 155177.

[15] Feather, N. T., \& Rauter, K. A. (2004). Organizational Citizenship Behaviours in Relation to Job Status, Job Insecurity, Organizational Commitment and Identification, Job Satisfaction and Work Values. Journal of Occupational \& Organizational Psychology, 77(1), 81-94.

[16] Fugate, M., Kinicki, A. J., \& Scheck, C. L. (2010). Coping with an Organizational Merger over Four Stages. Personnel Psychology, 55(4), 905-928.

[17] Glick, W. H., Huber, G. P., Miller, C. C., Doty, D. H., \& Sutcliffe, K. M. (1990). Studying Changes in Organizational Design and Effectiveness: Retrospective Event Histories and Periodic Assessments. Organization Science, 1(3), 293-312.

[18] Greenhalgh, L., \& Rosenblatt, Z. (1984). Job Insecurity: Toward Conceptual Clarity. Academy of Management Review, 9(3), 438-448.

[19] Griffin, M. A., Rafferty, A. E., \& Mason, C. M. (2004). Who Started This? Investigating Different Sources of Organizational Change. Journal of Business \& Psychology, 18(4), 555-570.

[20] Hellriegel, Slocum \& Woodman.(2001) .Organization Behavior (9th Ed.). Ohio: South-Western College Publishing.

[21] Hui, C. (2000). Moderating Effects of Organization-based Selfesteem on Organizational Uncertainty: Employee Response Relationships. Journal of Management, 26(2), 215-232.

[22] Korsgaard, M. A., Sapienza, H. J., \& Schweiger, D. M. (2002). Beaten before Begun: the Role of Procedural Justice in Planning Change. Journal of Management, 28(4), 497-516.

[23] Kotter, J . P, Si Cohen, D. S . (2002). The Heart of Change:Real-life Stories of How People Change Their Organizations.Boston:Harvard Business Review Press.

[24] Lattuch, F., \& Young, S. (2011). Young Professionals' Perceptions toward Organizational Change. Leadership \& Organization Development Journal,32(6), 605-627.

[25] Lazarus, R.S. \&Folkman, S. (1984).Stress, Appraisal, and Coping, Springer, New York, NY.

[26] Lee, T. W., \& Mitchell, T. R. (1994). An Alternative Approach: the Unfolding Model of Voluntary Employee Turnover. Academy of Management Review, 19(1), 51-89.
[27] Lewin, K.(1951).. Field Theory in Social Science.New York, NY: Harper and Row.

[28] Mauno, S., De Cuyper, N., Tolvanen, A., Kinnunen, U., \& Mäkikangas, A. (2014). Occupational Well-being as a Mediator between Job Insecurity and Turnover Intention: Findings at the Individual and Work Department Levels. European Journal of Work \& Organizational Psychology, 23(3), 381-393.

[29] Mishra, A. K., \& Spreitzer, G. M. (1998). Explaining how Survivors Respond to Downsizing: the Roles of Trust, Empowerment, Justice, and Work Redesign. Academy of Management Review, 23(3), 567588.

[30] Mobley, W. H. (1977). Intermediate Linkages in the Relationship between Job Satisfaction and Employee Turnover. Journal of Applied Psychology,62(2), 237-240.

[31] Preacher, K. J., \& Hayes, A. F. (2008). Asymptotic and Resampling Strategies for Assessing and Comparing Indirect Effects in Multiple Mediator Models. Behavior Research Methods, 40(3), 879.

[32] Rafferty, A. E., \& Griffin, M. A. (2006). Perceptions of Organizational Change: a Stress and Coping Perspective. Journal of Applied Psychology,91(5), 1154.

[33] Salter, K. M. (1998). Job Insecurity and Its Antecedents. Dissertation Abstracts International, Volume: 59-12, Section: B, page: 6508.;Major Professor: Howard.

[34] Vakola, M., \& Nikolaou, I. (2005). Attitudes towards Organizational Change: What Is the Role of Employees' Stress and Commitment? Employee Relations, 27(2), 160 - 174.

[35] Ven, A. H. V. D., \& Poole, M. S. (2005). Alternative Approaches for Studying Organizational Change. The Chemistry of cationic polymerization /. Pergamon Press. 